\title{
Editorial: Advances in Crop Resistance for Insect Pest Control
}

\author{
Cesar Rodriguez-Saona ${ }^{1 *}$, Elvira de Lange ${ }^{2}$ and Surendra K. Dara ${ }^{3 \dagger}$ \\ ${ }^{1}$ P. E. Marucci Center, Rutgers University, Chatsworth, NJ, United States, ${ }^{2}$ Department of Entomology and Nematology, \\ University of California, Davis, Davis, CA, United States, ${ }^{3}$ University of California Division of Agriculture and Natural \\ Resources, San Luis Obispo, CA, United States
}

Keywords: elicitors, biostimulants, genetic diversity, domestication, agriculture

\section{Editorial on the Research Topic}

\section{Advances in Crop Resistance for Insect Pest Control}

Crops are regularly challenged by insect pests, particularly in monoculture farming systems which are common at present in many agricultural areas. Genotypic and phenotypic diversity in plant traits such as nutritional quality, architecture, physical features, or ability to resist or tolerate pest damage can be explored to reduce pest populations in cropping systems (e.g., Wetzel et al., 2016). It is also known that, in response to herbivore attack, plants often change their phenotype to increase their defenses (Karban and Myers, 1989). These changes, termed induced plant resistance, include a reduction of the nutritional quality of plants for herbivores, increases in chemical and physical defenses, as well as increases in the emissions of volatiles that can attract the natural enemies of herbivores. Although plant resistance has been documented in many plant species, domestication is thought to have lowered the ability of plants to defend against herbivores (Chen et al., 2015; Whitehead et al., 2017). Thus, methods to enhance/restore the defensive responses of crops offer a promising avenue for controlling pests in agriculture. Notably, the activation of two defense pathways-the jasmonic acid (JA) and salicylic acid (SA) pathways-have been associated with induced resistance against insect herbivores (Thaler et al., 2012). Manipulation of these defense pathways to improve induced crop resistance constitutes a novel approach to insect pest control in agriculture (Bektas and Eulgem, 2015). For instance, elicitors or biostimulants of the JA, SA, and other defense pathways have been studied as an alternative for insect pest control (Stout et al., 2002). However, the approach of incorporating biostimulant application as an IPM tool for improved plant health and resistance against pests is recent (Dara, 2021), and needs to be further explored to its fullest potential (Figure 1). The objective of this Research Topic is to provide a forum for review and research papers on novel approaches and technologies for improved plant protection against insect pests. It contains five articles that focus on three main themes: (1) breeding for host-plant resistance against insect pests, (2) the potential of biostimulants in crop protection, and (3) the impact of crop domestication on host-plant resistance.

Screening for genetic sources of host-plant resistance is a key step in breeding programs toward managing insect pests in agriculture. Rondon et al. conducted a literature review on the genetic sources of resistance against the Colorado potato beetle, Leptinotarsa decemlineata, an important pest of potatoes. The authors discuss the biochemical and morphological traits of potatoes that might be responsible for providing resistance, current efforts to identify resistant genotypes, and new strategies to improve the efficiency of evaluation and selection of resistant genotypes. Furthermore, a critical aspect in farmer adoption of resistant cultivars is their performance for crop protection as an integral component of an IPM program. To address this, Villegas et al. showed that host-plant resistance can be combined with cultural control tactics, such as delayed flooding, as an alternative to insecticide seed treatments to reduce the incidence of both the rice water weevil, Lissorhoptrus oryzophilus, and stemborers in rice. 


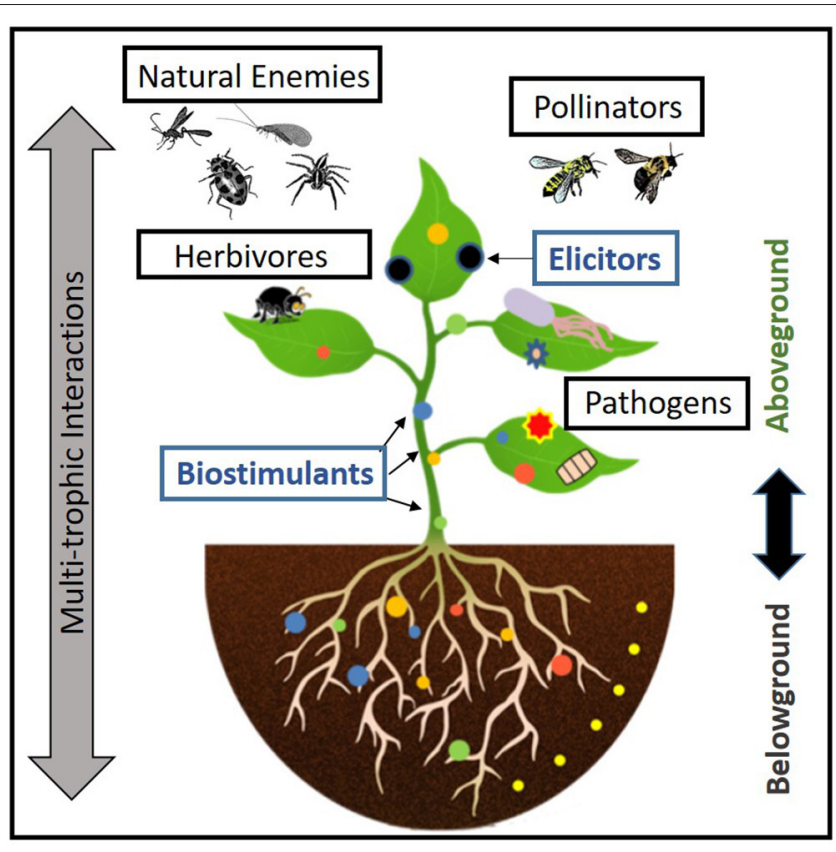

FIGURE 1 | A multi-organismal and multi-disciplinary approach for studying host-plant resistance against insect pests is needed that incorporates multi-trophic insect-microbial-plant interactions aboveground and belowground. Elicitors of the jasmonic acid and salicylic acid pathways and biostimulants such as growth promoting rhizobacteria and humic acids offer ways to enhance plant defense responses and improve plant growth Drawings by S. K. Dara and R. Holdcraft.

In another review paper, Pereira et al. examined the role of biostimulants, such as plant growth promoting rhizobacteria (PGPR) and humic acids (HA), in eliciting plant defenses against insect pests. The paper discusses the activation of induced defenses by these two biostimulants in a tri-trophic context that involves the crop, insect herbivores, and the herbivores' natural enemies, as well as the potential interactions between these biostimulants. The authors provide examples on the effects of PGPR and HA on insect herbivores and their natural enemies and argued that these biostimulants have the potential to enhance plant defenses and reduce pest populations, and thus provide an alternative to chemical control that can be incorporated into IPM programs.

Two papers in the Research Topic address the potential negative effects of crop domestication on resistance against herbivores. In one of these papers, Hernández-Cumplido et al. tested the "plant domestication-reduced defense" hypothesis (Gaillard et al., 2018) in avocados. This study used seven avocado genotypes across a domestication gradient and measured variation in plant traits, chemical defenses, and resistance against two leaf-chewing insect herbivores (a specialist and a generalist). The authors found no clear support for the "plant domestication-reduced defense" hypothesis in avocado, despite finding significant genotypic variation in plant traits, phenolic content, and resistance against the two herbivores. Jaccard et al. also tested this hypothesis in squash varieties domesticated for either consumption or as ornamentals, and that differ in plant defense traits and in their interactions with a leaf and a root herbivore. Similar to the study by Hernández-Cumplido et al., the authors found high variation in defenses (i.e., cucurbitacin content and leaf trichome density) among varieties, but no support for their hypothesis on reduced defenses in consumption varieties and, although herbivore preference differed, herbivore performance was not affected by squash variety. Although not directly linked to domestication, these two studies identified sources of genetic variation that could be used to enhance resistance against herbivores in crops such as avocado and squash.

In conclusion, due to increasing restrictions on insecticide use worldwide, there is growing interest in finding environmentallysafe and IPM-compatible alternative tactics to manage insect pests. Host-plant resistance has been an integral part of IPM since Painter (1951) introduced the concept in his seminal book "Insect Resistance in Crop Plants". However, there is still the need in many crops to implement host-plant resistance into IPM programs and to understand the mechanisms underlying herbivore resistance. An updated IPM model provides guidance for implementation of IPM in more cropping systems (Dara, 2019). Moreover, in recent years, studies have been conducted to identify potential sources of resistance against multiple plant antagonists, which could include the use of wild (ancestral) genotypes that are often more resistant than their domesticated counterparts in breeding programs, as well as tactics to enhance crop resistance using biostimulants or elicitors of plant defenses. Yet, future research is still needed to determine how these tactics may affect multiple organisms (detrimental and beneficial) living aboveground and belowground (Figure 1) under field conditions.

\section{AUTHOR CONTRIBUTIONS}

CR-S, EL, and SD contributed equally in organizing this Research Topic. CR-S wrote the first draft of this editorial based on the contributed articles. All authors contributed to the article and approved the submitted version.

\section{ACKNOWLEDGMENTS}

We thank the Frontiers in Agronomy Specialty Chief Editor for the opportunity to edit this Research Topic and the Journal Specialist for her consistent technical support. We are also thankful to all the authors who contributed to this Research Topic and the reviewers for critically evaluating the manuscripts. 


\section{REFERENCES}

Bektas, Y., and Eulgem, T. (2015). Synthetic plant defense elicitors. Front. Plant Sci. 5, 804. doi: 10.3389/fpls.2014.00804

Chen, Y. H., Gols, R., and Benrey, B. (2015). Crop domestication and its impact on naturally selected trophic interactions. Ann. Rev. Entomol. 60, 35-58. doi: 10.1146/annurev-ento-010814-020601

Dara, S. K. (2019). The new integrated pest management paradigm for the modern age. J. Integr. Pest Manag. 10, 12. doi: 10.1093/jipm/pmz010

Dara, S. K. (2021). "Advances in biostimulants as an integrated pest management tool in horticulture," in Improving Integrated Pest Management (IPM) in Horticulture, ed R. Collier (London: Burleigh Dodds Science Publishing), 33 pp.

Gaillard, M. D. P., Glauser, G., Robert, C. A. M., and Turlings, T. C. J. (2018). Fine-tuning the 'plant domestication-reduced defense' hypothesis: specialist vs generalist herbivores. New Phytol. 217, 355-366. doi: 10.1111/nph.14757

Karban, R., and Myers, J. H. (1989). Induced plant responses to nerbivory. Annu. Rev. Ecol. Syst. 20, 331-348. doi: 10.1146/annurev.es.20.110189.001555

Painter, R. H. (1951). Insect Resistance in Crop Plants. New York, NY: The Macmillan Co. 520 pp.

Stout, M. J., Zehnder, G. W., and Baur, M. E. (2002). Potential for the use of elicitors of plant resistance in arthropod management programs. Arch. Insect Biochem. Physiol. 51, 222-235. doi: 10.1002/arch.10066

Thaler, J. S., Humphrey, P. T., and Whiteman, N. K. (2012). Evolution of jasmonate and salicylate signal crosstalk. Trends Plant Sci. 17, 260-270. doi: 10.1016/j.tplants.2012.02.010
Wetzel, W. C., Kharouba, H. M., Robinson, M., Holyoak, M., and Karban, R. (2016). Variability in plant nutrients reduces insect herbivore performance. Nature. 539, 425-427. doi: 10.1038/nature 20140

Whitehead, S. R., Turcotte, M. M., and Poveda, K. (2017). Domestication impacts on plant-herbivore interactions: a meta-analysis. Phil. Trans. R. Soc. 372, 20160034. doi: 10.1098/rstb.2016.0034

Conflict of Interest: The authors declare that the research was conducted in the absence of any commercial or financial relationships that could be construed as a potential conflict of interest.

Publisher's Note: All claims expressed in this article are solely those of the authors and do not necessarily represent those of their affiliated organizations, or those of the publisher, the editors and the reviewers. Any product that may be evaluated in this article, or claim that may be made by its manufacturer, is not guaranteed or endorsed by the publisher.

Copyright (c) 2022 Rodriguez-Saona, de Lange and Dara. This is an open-access article distributed under the terms of the Creative Commons Attribution License (CC $B Y)$. The use, distribution or reproduction in other forums is permitted, provided the original author(s) and the copyright owner(s) are credited and that the original publication in this journal is cited, in accordance with accepted academic practice. No use, distribution or reproduction is permitted which does not comply with these terms. 